\title{
Sexual Diergism of Hypothalamo-Pituitary- Adrenal Cortical Responses to Low-Dose Physotigmine in Elderly vs. Young Women and Men
}

Robert T. Rubin, M.D., Ph.D., Michael E. Rhodes, Ph.D., Susan O'Toole, R.N., C.S., M.S.N., and R. Kenneth Czambel, B.S.

We previously demonstrated that the reversible cholinesterase inhibitor, physostigmine (PHYSO), administered to normal young adult women and men (average age 35 years) at a dose that produced few or no side effects, resulted in a sex difference (sexual diergism) in hypothalamo-pituitary-adrenal cortical (HPA) axis responses: Plasma ACTH $\mathrm{H}_{1-39}$, cortisol, and arginine vasopressin $(A V P)$ concentrations increased to a significantly greater extent in the men than in the women. To explore the effect of age on these sexually diergic hormone responses, in the present study we used the same dose of PHYSO (8 $\mu \mathrm{g} / \mathrm{kg} I V)$ to stimulate ACTH $\mathrm{H}_{1-39}$, cortisol, and AVP secretion in normal elderly, non-estrogen-replaced women and elderly men (average ages 73 years and 70 years, respectively). The subjects underwent three test sessions 5-7 days apart: PHYSO, saline control, and a second session of PHYSO. Serial blood samples were taken for hormone analyses before and after pharmacologic challenge.

As with the previously studied younger subjects, PHYSO administration produced no side effects in about half the elderly subjects and mild side effects in the other half, with no significant female-male differences. The hormone responses were 2-5 fold greater in the elderly subjects than in the younger subjects, but in contrast to the younger subjects, the elderly men did not have significantly greater hormone responses to PHYSO administration than did the elderly women. The ACTH $H_{1-39}$ and AVP responses to PHYSO for the two sessions were significantly positively correlated in the men $(+0.96,+0.91)$ but not in the women. None of the hormone responses was significantly correlated with the presence or absence of side effects in either group of subjects.

These results indicate a greater sensitivity of the HPA axis to low-dose PHYSO, and a loss of overall sex differences in hormone responses, in elderly compared with younger subjects. The lack of a difference in side effects between the elderly women and men and the lack of significant correlations between presence or absence of side effects and hormone responses suggest that the increase in hormone responses with aging is due to correspondingly increased responsiveness of central cholinergic systems and/ or the HPA axis, and not to a nonspecific stress response.

[Neuropsychopharmacology 26:672-681, 2002] (C) 2002 American College of Neuropsychopharmacology. Published by Elsevier Science Inc.
From the Center for Neurosciences Research, MCP Hahnemann University School of Medicine, Allegheny General Hospital, Pittsburgh, PA 15212.

Address correspondence to: Dr. Robert T. Rubin, Center for Neurosciences Research, Allegheny General Hospital, 320 East North Ave., Pittsburgh, PA 15212-4772, Tel.: (412) 359-3235; Fax: (412) 3594499, E-mail: rubin@wpahs.org
KEY WORDS: Cholinergic; Physostigmine; AVP; ACTH;

Cortisol; Aging; Sexual diergism

Received March 29, 2001; revised July 19, 2001; accepted September 20, 2001. 
Cholinergic neurotransmission stimulates both corticotropin releasing hormone $(\mathrm{CRH})$ and arginine vasopressin (AVP) secretion (Gregg 1985; Tuomisto and Männistö 1985; Assenmacher et al. 1987; Tsagarakis and Grossman 1990; Michels et al. 1991; Okuda et al. 1993; Whitnall 1993; Coiro et al. 1995; Calogero 1995; Ohmori et al. 1995; Pascualy et al. 1995), both of which stimulate adrenocorticotropic hormone (ACTH) secretion (Rivier et al. 1990; Antoni 1993). Because cholinergic agonists produce noxious side effects, especially nausea, and by inference a nonspecific stress response, we established a dose of physostigmine (PHYSO), a reversible cholinesterase inhibitor, that discernibly elevated plasma ACTH and cortisol concentrations in normal young adult subjects but produced few or no side effects (Rubin et al. 1999a). The purpose was to develop a specific pharmacologic cholinergic challenge to the central nervous system, with which to test the cholinergic overactivity hypothesis of major depression (Janowsky and Overstreet 1995), as reflected by hypothalamo-pituitary-adrenal cortical (HPA) axis hormone responses in patients compared with controls (Rubin et al. 1999b). An interesting outcome of the dose-finding studies in the young adult subjects was a clear functional sex difference (sexual diergism; Rhodes and Rubin 1999) of $\mathrm{ACTH}_{1-39}$, cortisol, and AVP responses: The men had significantly greater hormone responses to PHYSO $(8 \mu \mathrm{g} / \mathrm{kg})$ than did the women (Rubin et al. 1999a).

PHYSO challenge also has been used in elderly subjects to investigate the neuroendocrine effects of aging and Alzheimer's disease (Raskind et al. 2001). Raskind et al. (1990) found significantly greater cortisol and $\beta$-endorphin-like immunoactivity ( $\beta E-L I)$ responses to PHYSO $(12.5 \mu \mathrm{g} / \mathrm{kg}$ infused IV over 10 min), but no significant difference in AVP responses, in 12 healthy elderly men (average age 68 years) compared with nine healthy young men (average age 25 years). Peskind et al. (1995, 1996), using the same PHYSO challenge, studied five female and five male healthy, elderly controls (average age 71 years), and three female and eight male otherwise healthy patients with probable Alzheimer's disease (average age 72 years). The patients and controls had similar $\mathrm{ACTH}, \beta \mathrm{E}-\mathrm{LI}$, and cortisol responses, but the group of eight women had significantly greater responses of all three hormones than did the 13 men. There were similarly greater responses of all three hormones in the five normal elderly women compared with the five normal elderly men (Peskind et al. 1995). These findings suggested a sexual diergism of HPA axis responses in elderly subjects the opposite of that which we found in young adult subjects (Rubin et al. 1999a), prompting the present study of elderly women and men given the same PHYSO challenge we used in our younger subjects.

\section{SUBJECTS AND METHODS}

\section{Development of a Low-Dose Physostigmine Challenge Test}

In five normal men, ages 25-30 years, Lewis et al. (1984) found that, following peripheral cholinergic blockade, a PHYSO dose of $18 \mu \mathrm{g} / \mathrm{kg}$ produced both unpleasant side effects (nausea, fatigue, headache) and increased ACTH and cortisol secretion, whereas lower doses (6 and 12 $\mu \mathrm{g} / \mathrm{kg}$ ) produced neither side effects nor HPA axis activation. We therefore began dose-finding studies in normal women and men with PHYSO (12 $\mu \mathrm{g} / \mathrm{kg}$ IV over 1-2 min). The details of the four dose-finding studies have been presented earlier (Rubin et al. 1999a). In contrast to Lewis et al. (1984), who found no HPA axis response to PHYSO (12 $\mu \mathrm{g} / \mathrm{kg})$, in our subjects the best compromise between hormone responses and minimalto-no side effects occurred at a PHYSO dose of $8 \mu \mathrm{g} / \mathrm{kg}$.

We started with this dose of PHYSO in the present study, but because we had an occasional subject who experienced severe side effects with this dose, as described below, we administered a $4 \mu \mathrm{g} / \mathrm{kg}$ dose to some elderly subjects, which resulted in neither side effects nor measurable hormone responses. We therefore returned to the higher dose; all the subjects in the present study received PHYSO $(8 \mu \mathrm{g} / \mathrm{kg})$ and had minimal to no side effects.

\section{Subjects}

Subjects $\geqslant 65$ years of age were recruited through lay and religious senior citizens' groups, hospital employees' families and friends, newsletters, and public service announcements. Initial telephone screening of more than 400 individuals led to the scheduling of 43 intake evaluations; many of the other responders were eliminated on the basis of reported concurrent illnesses and medications potentially interfering with the neuroendocrine testing.

During the intake evaluation the Institutional Review Board-approved experimental protocol was explained in detail, and written informed consent was obtained. Next, the absence of past or present psychiatric illness was determined with the Structured Clinical Interview for DSM-IV, Non-Patient Version (First et al. 1996), conducted by a master's level psychiatric nurseclinician and verified by a psychiatrist. The Hamilton Depression Rating Scale (Hamilton 1967) also was completed on each subject; Hamilton scores were all $\leqslant 1$.

A physical assessment, complete blood count, urinalysis and urine screen for common drugs of abuse, blood chemistry panel including thyroid indices, electrocardiogram, and chest X-ray then were obtained. Anyone with a history of major medical illness such as hypertension, diabetes, or other endocrinopathy; with abnormal physical or laboratory findings; or who was on any 
medication that might interfere with the endocrine testing was excluded. Of the 43 subjects evaluated in person, three refused participation and were not evaluated further, nine had abnormal electrocardiograms, three were hypothyroid, two had other interfering medical conditions, two were found to be taking an anticholinergic drug for urinary urgency, two were not cleared for participation by their primary care physicians, two had positive screens for illicit or interfering drugs, and one had estrogen levels in the premenopausal range, suggesting she had received estrogen replacement therapy. Of the subjects who started the protocol, one had such severe vasoconstriction on two occasions that no blood could be drawn, and four had such severe side effects following PHYSO that treatment with dolasetron for nausea was required. These five were not studied further. This detail is given to highlight the relative difficulty in recruiting the elderly subjects included herein.

Eight normal elderly women and six normal elderly men met all inclusion and exclusion criteria and successfully completed the protocol. All were caucasian. None of the women was receiving estrogen replacement therapy. One of the women was receiving thyroid replacement; her thyroid indices were normal. Six of the women and all six men were non-smokers; two of the women smoked 20-30 cigarettes per day.

\section{Neuroendocrine Protocol}

Each subject underwent three test sessions, 5-7 days apart, in the Clinical Studies Suite of Allegheny General Hospital. The order of the sessions was (1) PHYSO (8 $\mu \mathrm{g} / \mathrm{kg}$ IV), (2) saline control, and (3) PHYSO (8 $\mu \mathrm{g} / \mathrm{kg}$, IV). The PHYSO session was repeated, because in our earlier studies there was a decrement in hormone response from the first to the second PHYSO administration (Rubin et al. 1999a, 1999b).

Subjects were admitted for study at 1:30 P.M. A heparin-lock catheter was inserted into an arm vein, and 6 $\mathrm{ml}$ blood was taken every $30 \mathrm{~min}$ starting at 2:30 P.M. At 5 P.M., a very light meal was given. At 5:30 P.M., glycopyrrolate $(0.2 \mathrm{mg}$ IM) was given to block the peripheral effects of PHYSO. At 6 P.M., PHYSO in varying doses or an equivalent amount of saline was given IV over 1-1.5 min. Blood was drawn every 5 min from 6 P.M. until 6:20 P.M., every 10 min until 7 P.M., and then every 30 min until 10 P.M. (22 samples; a total of $132 \mathrm{ml}$ ).

All plasma samples from each subject were analyzed in the same $\mathrm{ACTH}_{1-39}$, cortisol, and AVP assays, in duplicate for the first two hormones and in singlet for AVP. The parameters of the $\mathrm{ACTH}_{1-39}$ immunoradiometric assay (IRMA) and the cortisol and AVP radioimmunoassays (RIA) have been described earlier (Rubin et al. 1987, 1995, 1999a). Plasma estrogen and testosterone were quantitated by RIA in the 4 P.M. samples on each of the three test days; the parameters of these RIAs also have been described earlier (Rubin et al. 1999b).

Side effects were quantified on a 4-point scale (0-3; none, mild, moderate, severe) at three times during each session. After the 5:30 P.M. injection (glycopyrrolate) the criteria were: $0=$ none, $1=$ metallic taste $/ \mathrm{mild}$ dry mouth; 2 = prolonged mild dry mouth, $3=$ prolonged severe dry mouth. After the 6 P.M. injection (PHYSO or saline) the criteria were: $0=$ none, $1=$ transient lightheadness/nausea, 2 = prolonged lightheadedness/nausea, 3 = vomiting.

Because, as indicated above, four subjects who initially started the protocol had such severe side effects following PHYSO that the protocol was stopped, red blood cell (RBC) acetylcholinesterase and plasma (pseudo)cholinesterase activities were determined in all the subjects. RBC acetylcholinesterase was assayed by the Mayo Clinic, Rochester, MN, with an in-house modification of the method of Ellman et al. (1961). Inter-assay variability was $<6 \%$, and assay sensitivity was $5 \mathrm{U} / \mathrm{g}$ hemoglobin $(\mathrm{Hb})$. Plasma cholinesterase was assayed by the method of the German Society for Clinical Chemistry (Anonymous 1992). Inter-assay variability was $<2 \%$, and assay sensitivity was $0.2 \mathrm{U} / \mathrm{ml}$.

\section{Statistical Analysis}

For ACTH and cortisol the values between 2:30 P.M. and 6 P.M. served as baseline. AVP was measured in the samples between 4:30 P.M. and 7 P.M., so that values between 4:30 P.M. and 6 P.M. served as baseline. Areas under the curve (AUC) were calculated by the trapezoidal rule and used as the measures of hormone response to PHYSO. For $\mathrm{ACTH}_{1-39}$, the response was the AUC between 6 P.M. and 8 P.M., by which time plasma ACTH was back to baseline. For cortisol, the response was the AUC between 6 P.M. and 10 P.M., when sampling stopped. For AVP, the response was the AUC between 6 P.M. and 7 P.M., by which time plasma AVP was almost back to baseline.

Repeated-measures analyses of variance (ANOVAs) were used to compare the hormone response AUCs by sex and across the test days, with post-hoc multiple comparisons (Duncan multiple range tests) where appropriate. Because the values for all the hormones were log-distributed across subjects, the data were log-transformed prior to parametric statistical analysis. Pearson product-moment correlations also were calculated on the log-transformed data. All reported significance levels are 2-tailed. Statistically significant differences are considered as $p<.05$, and trends as $.05<p<.10$.

\section{RESULTS}

The mean ( \pm S.E.M.) ages were $73 \pm 2.0$ years for the women and $70 \pm 1.4$ years for the men, a nonsignificant 
difference. Baseline plasma estrogen and testosterone concentrations were within the postmenopausal range for all eight women and within the normal elderly range for all six men (Fisher and Nelson 2001). Body surface area (BSA) was significantly less in the women $\left(1.63 \pm 0.05 \mathrm{~m}^{2}\right)$ than in the men $\left(2.01 \pm 0.09 \mathrm{~m}^{2}\right)(\mathrm{t}=$ 3.89; $\mathrm{df}=12 ; p<.003)$. Correlations between BSA and baseline and stimulated hormone values in both the women and the men were all of low order.

\section{Side Effects of Drug Administration}

Table 1 indicates the numbers of female and male subjects having no, mild, or moderate side effects following administration of glycopyrrolate at 5:30 P.M. and saline or PHYSO at 6 P.M. Side effects were graded as indicated above and in the table legend. About half the subjects had no side effects, and no subject had severe side effects following any treatment. One woman had moderate reaction to glycopyrrolate, and a different woman had a moderate reaction to PHYSO, on the first PHYSO day. All other side effects were rated as mild.

The few moderate side effects were combined with the mild side effects to create dichotomous scores (side effects absent or present), and Mann-Whitney rank-sum tests were calculated on these scores. As indicated in Table 1, PHYSO produced a greater frequency of side effects in both the women and the men than did saline. Glycopyrrolate produced a significant female-male difference in frequency of side effects only on the last of the three test days (none of the men had any side effects on that day). There were no significant female-male dif- ferences in side effects following PHYSO on either of the two days. There also was no across-subjects consistency in occurrence of side effects following glycopyrrolate across the three test sessions, or following PHYSO across the two PHYSO test sessions, for either the women or the men (Kendall's coefficients of concordance all low [0.00-0.25] and nonsignificant).

Of importance, point biserial correlations between side effects (absent or present) after PHYSO administration at 6 P.M. on the two PHYSO days and the corresponding $\mathrm{ACTH}_{1-39}$, cortisol, and AVP responses (AUCs) were generally of low order and nonsignificant. An exception was the correlations between absence or presence of side effects and the hormone AUCs for the men on the first PHYSO day; r values ranged between +0.88 and +0.94 (all significant at $p<.025$ ). However, on the second PHYSO day these correlations were all of low order $(+0.13-+0.46)$ and nonsignificant, and the hormone AUCs on this day were all greater than those on the first PHYSO day. This inconsistency in the men, along with all the correlations between side effects and hormone AUCs in the women being of low order, suggests that the hormone responses reported below cannot be attributed primarily to the occurrence of side effects in either group of subjects.

\section{Baseline RBC and Plasma Anticholinesterase Activities}

Mean ( \pm S.E.M.) RBC acetylcholinesterase was $46 \pm 1.1$ $\mathrm{U} / \mathrm{g} \mathrm{Hb}$ (range $=41-50$ ) in the women and $45 \pm 2.4$ $\mathrm{U} / \mathrm{g} \mathrm{Hb}$ (range $=39-52$ ) in the men. Both sets of values

Table 1. Number of Subjects Having No, Mild, or Moderate Side Effects, Respectively, Following Glycopyrrolate and Physostigmine (PHYSO) Challenge in Eight Normal Elderly Women Compared to Six Normal Elderly Men ${ }^{a}$

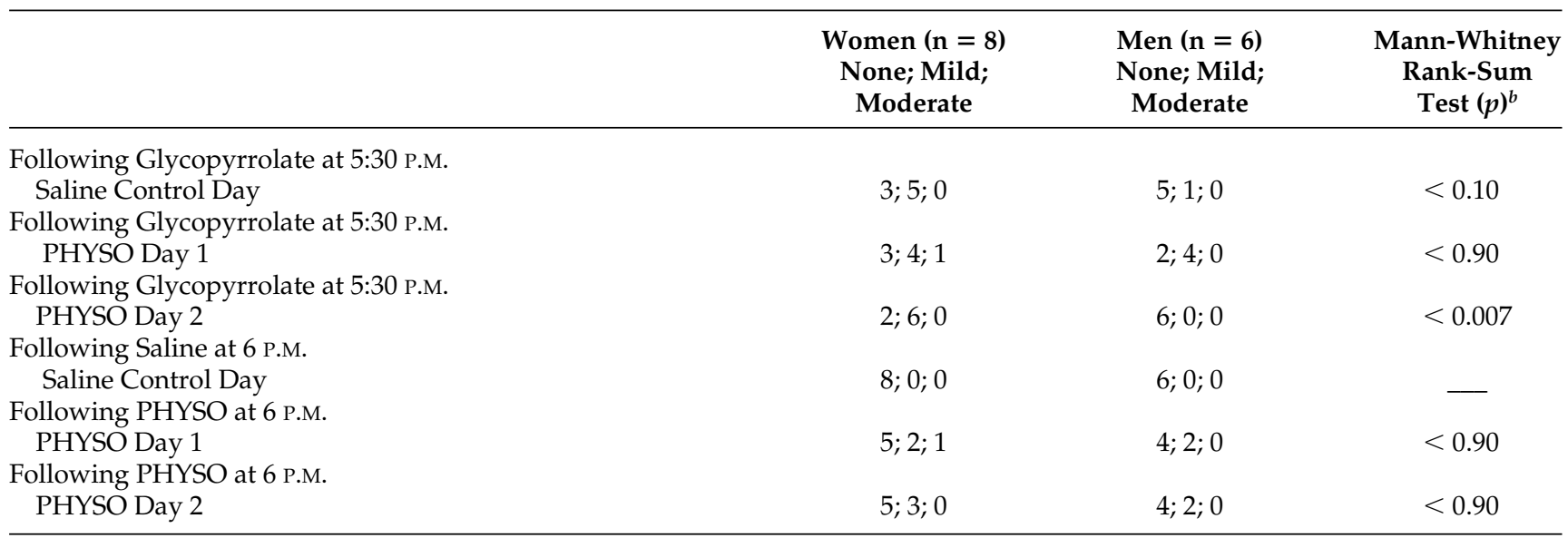

aSide effects were graded as follows (no subject had severe side effects following any treatment):

Following glycopyrrolate at 5:30 PM: $0=$ none; $1=$ metallic taste, mild dry mouth; $2=$ prolonged dry mouth; $3=$ prolonged severe dry mouth.

Following saline or PHYSO at 6 PM: $0=$ none; $1=$ mild (transient lightheadedness, nausea); $2=$ moderate (prolonged lightheadedness, nausea); $3=$ severe (vomiting).

${ }^{b}$ For the Mann-Whitney rank-sum tests, the few moderate side effects were combined with the mild side effects to create dichotomous scores (side effects absent or present), and the statistical tests were run on these scores. 
are within the normal range established on 20 individuals ages 23-37 years (J.F. O'Brien, Mayo Clinic, personal communication). There appears to be a decrement in RBC acetylcholinesterase activity in women $>65$ years of age but not in men (McWilliam et al. 1990); nevertheless, enzyme activities in our elderly female and male subjects

Table 2. Baseline $\mathrm{ACTH}_{1-39}$, Cortisol, and AVP and Hormone Responses to Physostigmine (PHYSO) Challenge in 8 Normal Elderly Women Compared to 6 Normal Elderly Men $^{a}$

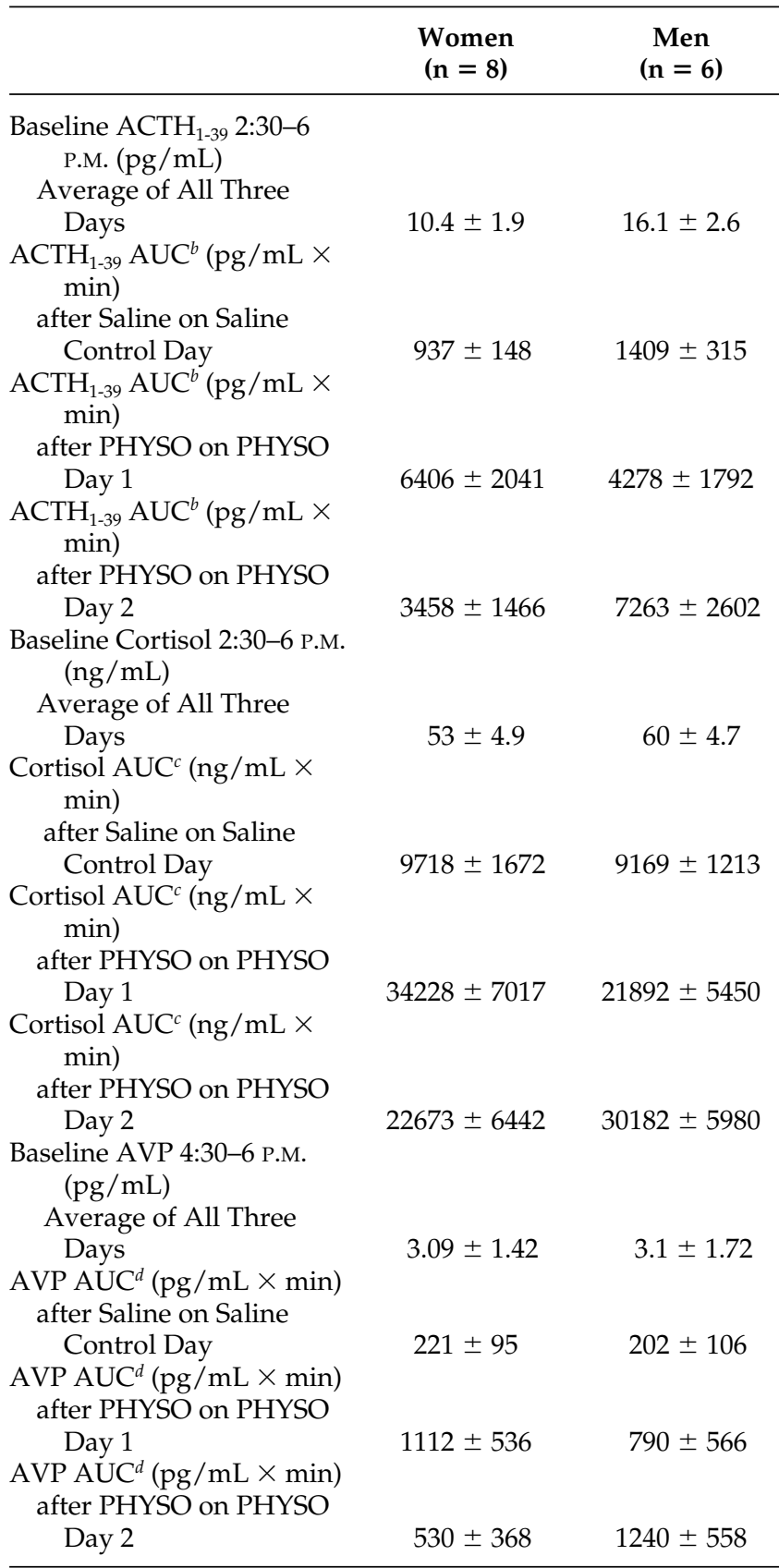

${ }^{a}$ Values are given as mean \pm standard error of the mean.

${ }^{b} \mathrm{ACTH}_{1-39} \mathrm{AUC}=$ area under the curve 6 P.M. -8 P.M.

${ }^{c}$ Cortisol AUC $=$ area under the curve 6 P.M. -10 P.M.

${ }^{d} \mathrm{AVP}$ AUC $=$ area under the curve 6 P.M. -7 P.M. were in the normal young-adult range. Mean $( \pm$ SEM) plasma (pseudo)cholinesterase was $8.2 \pm 0.42 \mathrm{U} / \mathrm{ml}$ (range $=6.7-9.9$ ) in the women and $8.9 \pm 0.44 \mathrm{U} / \mathrm{ml}$ (range $=6.8-10.1$ ) in the men, these values being in the normal range for elderly individuals (Genç et al. 1997).

For both the women and the men, point biserial correlations between the presence or absence of side effects and activities of the two cholinesterases were low, and only a few correlations were negative. Of interest, the four subjects (three female, one male) who had severe side effects following the first PHYSO dose and were excluded from study all had normal RBC and plasma cholinesterase values (ranges $=41-54 \mathrm{U} / \mathrm{g} \mathrm{Hb}$ and 6.9$11 \mathrm{U} / \mathrm{ml}$, respectively).

\section{Baseline Hormone Values and Hormone Responses to Drug Challenge}

Afternoon baseline $\mathrm{ACTH}_{1-39}$, cortisol, and AVP did not vary systematically across the three test days (Kendall's coefficients of concordance determined separately for each hormone and subject group were all $<0.25$; $p=$ NS). The baseline values of these stress-responsive hormones were not higher on the first versus the second or third test days (PHYSO-1, saline, and PHYSO-2, respectively), arguing against the possibility that the hormone responses to PHYSO administration were related to the order of testing; i.e., enhanced by the novelty of the experimental situation on the first test day. The different patterns of hormone responses across the two PHYSO days in the women versus the men (see below) also argue against this possibility.

Table 2 presents the mean ( \pm S.E.M.) baseline hormone values and the hormone responses to saline and PHYSO (AUCs) in the female and male subjects. Because the baseline hormone values did not vary systematically across the three test days, as noted above, they were averaged across the three days for each subject. Afternoon baseline $\mathrm{ACTH}_{1-39}$ was marginally higher in the men than in the women $(\mathrm{t}=1.74 ; \mathrm{df}=12 ; p=.11)$, but baseline cortisol and AVP were not significantly different between groups $(t=1.14$ and -0.03 , respectively).

ANOVAs were performed on the log-transformed $\mathrm{ACTH}_{1-39}$, cortisol, and AVP responses (AUCs) to PHYSO versus saline (repeated measures) in the female versus the male subjects (independent groups). For the PHYSO versus saline comparisons, the average hormone response on the two days in which PHYSO was administered at 6 P.M. was contrasted with the day in which saline was given at 6 P.M. PHYSO significantly increased the secretion of all three hormones $(p<.002, .002$, and .04 , respectively), but there was neither a significant sex difference nor a significant sex $\times$ treatment (PHYSO vs. saline) interaction for any of the hormones (all $p$ values $>.40$ ).

Because the women appeared to have greater responses of all three hormones on PHYSO Day 1 com- 
pared with PHYSO Day 2 and the men showed the opposite (Table 2), repeated-measures ANOVAs also were performed on the hormone responses on PHYSO Day 1 versus PHYSO Day 2 in the female versus the male subjects. There was a strong trend toward a significant sex $\times$ PHYSO day interaction for $\mathrm{ACTH}_{1-39}(p<.06)$, and there were clearly significant sex $\times$ PHYSO day interactions for cortisol and AVP $(p<0.03$ and 0.025, respectively), supporting the finding that the women and men responded differently across the two PHYSO test days.

Correlations between the $\mathrm{ACTH}_{1-39}$ and AVP responses to PHYSO on the two PHYSO days were +0.96 and +0.91 , respectively, for the men, both being significant (both $p$ values $<.01$ ), whereas they were only +0.62 and +0.46 , respectively, for the women, both being nonsignificant.

Finally, Table 3 presents mean ( \pm S.E.M.) age, BSA, baseline hormone values, and hormone responses to sa- line and PHYSO (AUCs) for the elderly female and male subjects of this study and for the young female and male subjects reported previously (Rubin et al. 1999a). Significance values for ANOVAs across the four groups of subjects also are given in Table 3; multiple comparisons between groups were performed where indicated by a significant ANOVA and are reported below. To permit direct comparison across the four groups, the AUCs for the elderly women and men were recalculated in the same way as the AUCs for the younger subjects; i.e., using the 6 P.M., 6:30 P.M., and 7 P.M. values (Rubin et al. 1999a). These "abbreviated" AUCs in the elderly subjects were all highly correlated with the full AUCs reported in Table 2 (all $\mathrm{r}$ values $>+0.90$; most $>+0.98$ ).

The elderly subjects were twice the age of the young subjects. As would be expected, BSA was significantly lower in the women as a group compared with the men $(p<.01)$ and significantly lower in the elderly women compared with the young women $(p<.05)$. As also

Table 3. Age, Body Surface Area, Baseline Gonadal Steroids, $\mathrm{ACTH}_{1-39}$, Cortisol, and AVP, and Pituitary-Adrenal Hormone Responses to Physostigmine (PHYSO) Challenge in Eight Normal Elderly Women, 14 Normal Young Women, Six Normal Elderly Men, and 14 Normal Young Men ${ }^{a}$

\begin{tabular}{|c|c|c|c|c|c|}
\hline & $\begin{array}{c}\text { Elderly } \\
\text { Women } \\
(n=8)\end{array}$ & $\begin{array}{l}\text { Young } \\
\text { Women } \\
(n=14)\end{array}$ & $\begin{array}{c}\text { Elderly } \\
\text { Men } \\
(n=6)\end{array}$ & $\begin{array}{c}\text { Young } \\
\text { Men } \\
(n=14)\end{array}$ & $\begin{array}{c}\text { ANOVA }^{b} \\
p \text { Value } \\
(\mathrm{df}=3,38)\end{array}$ \\
\hline Age (years) & $73 \pm 2.0$ & $35 \pm 2.4$ & $70 \pm 1.4$ & $35 \pm 2.5$ & ـ \\
\hline Body Surface Area $\left(\mathrm{m}^{2}\right)$ & $1.63 \pm 0.05$ & $1.75 \pm 0.04$ & $2.01 \pm 0.09$ & $2.03 \pm 0.65$ & $<0.0001$ \\
\hline Average Estradiol $(\mathrm{pg} / \mathrm{ml})^{c}$ & $19 \pm 4.2$ & $43 \pm 27$ & $24 \pm 3.6$ & $25 \pm 9.2$ & \\
\hline Average Testosterone $(\mathrm{ng} / \mathrm{ml})^{c}$ & $0.18 \pm 0.03$ & $0.30 \pm 0.14$ & $2.5 \pm 0.3$ & $3.5 \pm 0.7$ & $\longrightarrow$ \\
\hline \multicolumn{6}{|l|}{ Average Baseline $\mathrm{ACTH}_{1-39}$} \\
\hline 2:30-6 P.M. $(\mathrm{pg} / \mathrm{mL})^{c}$ & $10.4 \pm 1.9$ & $10.1 \pm 1.4$ & $16.1 \pm 2.6$ & $15.4 \pm 1.7$ & $<0.05$ \\
\hline \multicolumn{6}{|l|}{ Average $\mathrm{ACTH}_{1-39} \mathrm{AUC}^{d, e}$} \\
\hline$(\mathrm{pg} / \mathrm{mL} \times \mathrm{min})$ after Saline & $532 \pm 90$ & $638 \pm 96$ & $705 \pm 144$ & $851 \pm 100$ & $<0.20$ \\
\hline \multicolumn{6}{|l|}{ Average $\mathrm{ACTH}_{1-39} \mathrm{AUC}^{d, \mathrm{f}}$} \\
\hline \multicolumn{6}{|l|}{ Ratio of Responses } \\
\hline PHYSO:Saline & $5.4: 1$ & $1.1: 1$ & $5.8: 1$ & $2.4: 1$ & \\
\hline \multicolumn{6}{|l|}{ Average Baseline Cortisol } \\
\hline 2:30-6 P.M. $(\mathrm{ng} / \mathrm{mL})^{c}$ & $53 \pm 4.9$ & $66 \pm 5.1$ & $60 \pm 4.7$ & $61 \pm 3.3$ & $<0.30$ \\
\hline \multicolumn{6}{|l|}{ Average Cortisol AUC ${ }^{d, e}$} \\
\hline (ng/mL $\times \min )$ after Saline & $3206 \pm 565$ & $3876 \pm 406$ & $2830 \pm 579$ & $3532 \pm 417$ & $<0.60$ \\
\hline $\begin{array}{l}\text { Average Cortisol AUC } \\
\text { (ng/mL } \times \text { min) after PHYSO }\end{array}$ & $6005 \pm 909$ & $4189 \pm 483$ & $7060 \pm 1321$ & $4426 \pm 621$ & $<0.15$ \\
\hline \multicolumn{6}{|l|}{ Ratio of Responses } \\
\hline PHYSO:Saline & $1.9: 1$ & 1.1:1 & $2.5: 1$ & $1.2: 1$ & \\
\hline \multicolumn{6}{|l|}{ Average Baseline AVP } \\
\hline \multicolumn{5}{|l|}{ Average AVP AUC } & $<0.02$ \\
\hline$(\mathrm{pg} / \mathrm{mL} \times \mathrm{min})$ after Saline & $221 \pm 95$ & $92 \pm 20$ & $201 \pm 103$ & $84 \pm 9.4$ & $<0.50$ \\
\hline \multicolumn{6}{|l|}{ Average AVP AUC ${ }^{d, \mathrm{f}}$} \\
\hline \multicolumn{6}{|l|}{ Ratio of Responses } \\
\hline PHYSO:Saline & $3.8: 1$ & 1.0:1 & $5.2: 1$ & $2.7: 1$ & \\
\hline
\end{tabular}

${ }^{a}$ Values are given as mean \pm standard error of the mean.

${ }^{b}$ ANOVAs performed on raw data for BSA and log-transformed data for all hormone measures.

${ }^{c}$ Average baselines $=$ average of three test days for elderly subjects and four test days for young subjects.

${ }^{d}$ AUCs for all three hormones $=$ area under the curve for 6 P.M., 6:30 P.M., and 7 P.M. values.

${ }^{e}$ Average AUCs = average of one saline test day for elderly subjects and two saline test days for young subjects.

${ }^{f}$ Average AUCs $=$ average of two PHYSO test days for both elderly and young subjects. 
would be expected, baseline estradiol in the non-estrogen-replaced, elderly women was in the postmenopausal range, being half that in the young women and similar to baseline estradiol in both groups of men, which also were in the normal range (Fisher and Nelson 2001). Baseline testosterone in the elderly women was two-thirds that in the younger women, both being in the normal range for their respective age groups (Fisher and Nelson 2001).

There was a trend toward higher baseline $\mathrm{ACTH}_{1-39}$ in the men as a group compared with the women $(p<.10)$, with no significant difference by age. Baseline cortisol was not significantly different across groups. Baseline AVP was significantly higher in the elderly subjects as a group compared with the young subjects as a group $(p<$ .05), with no significant difference based on sex.

Following saline administration, the AUCs for all three hormones were not significantly different across groups, owing to considerable across-subjects variability, even though the mean responses across groups followed similar patterns as the baseline hormone values (i.e., somewhat higher $\mathrm{ACTH}_{1-39} \mathrm{AUCs}$ in the men; somewhat higher AVP AUCs in the elderly). On the other hand, the $\mathrm{ACTH}_{1-39}$ AUC following PHYSO administration was highly significantly different across groups, owing to a significantly lower ACTH AUC in the young women compared with the other three groups $(p<.01)$. As well, the AVP AUC following PHYSO administration was highly significantly different across groups, representing a significantly higher response in the elderly compared with the young subjects $(p<.01)$, similar to the significant age difference in baseline AVP. (The significant male-female difference in the AVP response to PHYSO in the young subjects had been reported previously [Rubin et al. 1999a]).

\section{DISCUSSION}

There are two main findings in this study. First, the HPA axis responses to cholinergic stimulation by PHYSO were higher in both the elderly women and the elderly men compared with their younger counterparts. This has been noted previously for elderly men (Raskind et al. 1990) but not studied to date in elderly women. The findings accord with the generally increased responsiveness of the HPA axis to several stimuli with advancing age (Seeman and Robbins 1994), likely due, at least in part, to decreased sensitivity of hippocampal and hypothalamic glucocorticoid negative feedback mechanisms (Ferrini et al. 1999; Hibberd et al. 2000). In the elderly, hypercortisolemia is hypothesized to be one factor in the development of hippocampal damage and subsequent cognitive dysfunction (Lupien et al. 1999; McEwen 1999; Hibberd et al. 2000; Ferrari et al. 2001).
Second, there appears to be no overall sex difference in HPA axis responses to cholinergic stimulation by PHYSO in elderly men compared with elderly, nonestrogen-replaced women, in contrast to the significantly greater hormone responses to PHYSO challenge occurring in young adult men compared with young adult women (Rubin et al. 1999a). In the elderly subjects, there was, however, apparent sexual diergism in hormone responses on the two PHYSO test days: Women responded more strongly on the first test day, whereas men responded more strongly on the second test day (significant sex $\times$ PHYSO test day interactions for all three hormones). No such interactions occurred in the younger subjects (Rubin et al. 1999a), and the reason for their occurrence in the elderly is unclear. Finally, in the elderly subjects, as in the younger subjects, there was little or no relationship between presence or absence of side effects following PHYSO and any of the hormone responses.

Other findings include a marginally higher baseline $\mathrm{ACTH}$ in the elderly men versus the elderly women and a significantly higher baseline AVP and AVP response to PHYSO in the elderly subjects as a group versus the younger subjects.

The normal RBC and plasma cholinesterase activities in the four subjects who experienced severe side effects following PHYSO and who were dropped from the study suggest the possibility of a greater sensitivity of brain versus $R B C$ acetylcholinesterase to inhibition by PHYSO, since different enzyme forms have been reported (Boschetti et al. 1996). Promoter polymorphisms have been described in the acetylcholinesterase gene (7q22; Ehrlich et al. 1992), a 4-bp deletion having been found in one person who had acute hypersensitivity to the cholinesterase inhibitor, pyridostigmine, and another individual who had hyperemesis gravidarum (Shapira et al. 2000). Similar promoter polymorphisms might have occurred in our subjects; we are investigating this possibility. Another possibility is a greater sensitivity of muscarinic receptors to increased synaptic acetylcholine in the brain-stem circuitry controlling nausea and emesis (area postrema; nucleus tractus solitarius) compared with muscarinic receptor sensitivity in the less severely reacting subjects. Only one of our four subjects with severe reactions to PHYSO reported having difficulty during surgical anesthesia, the nature of which was not known.

The marginally higher baseline ACTH concentrations in the elderly men compared with the elderly women likely were due to the greater body size (BSA) in the men (Rubin et al. 1996). Baseline cortisol and AVP were similar in the two groups, consistent with other reports of baseline cortisol in the elderly (Seeman and Robbins 1994), but in contrast to reports of higher serum AVP in elderly men versus elderly women (Asplund and Åberg 1991). 
With reference to hormone responses to cholinergic stimulation, Peskind et al. (1996) reported significantly higher ACTH, $\beta E-L I$, and cortisol responses to PHYSO in a group of elderly women (Alzheimer's disease patients and normal controls) compared with a similar group of elderly men, as mentioned earlier. These findings are different from ours, in that we found no overall sex difference in HPA axis responses to PHYSO in our elderly subjects.

It is difficult to reconcile the findings of these two studies. The average age of the Peskind et al. subjects was $71 \pm 2$ years, close to that of our subjects. There are some differences: Three of their eight elderly women were receiving estrogen replacement, in contrast to none of our eight elderly women, although Peskind et al. did state that the hormone responses of their two groups of women were similar. All their subjects were nonsmokers, whereas two of our eight women did smoke; however, the baseline and stimulated hormone values in the two smokers were similar to those in the other women. Peskind et al. administered $12.5 \mu \mathrm{g}$ PHYSO/kg IV over $10 \mathrm{~min}$, whereas we administered 8 $\mu \mathrm{g} / \mathrm{kg}$ IV over 1-1.5 min. They quantitated side effects to PHYSO and indicated there was no significant difference in nausea ratings between men and women, but the severity of side effects was not noted; i.e., how many subjects may have had nausea and vomiting and thus a nonspecific stress stimulation of the HPA axis. We measured the complete $\mathrm{ACTH}_{1-39}$ peptide by a highly specific IRMA, whereas Peskind et al. measured ACTH by RIA, which, depending on the antibody, can include smaller peptide fragments as well as the full 39 amino-acid sequence-their ACTH values were 50$100 \%$ higher than ours. The other hormone measured in both studies is cortisol, determined by specific RIA, and the values are similar, so the sex difference in the cortisol data between the two studies remains to be explained.

In our elderly men, as in the younger men (Rubin et al. 1999a), the AVP and $\mathrm{ACTH}_{1-39}$ responses to PHYSO were significantly positively correlated, suggesting that increased AVP may have been an intermediary between the cholinergic stimulus and the ACTH response. AVP-producing neurons in the human supraoptic (SON) and paraventricular (PVN) nuclei remain intact in old age (Hofman 1997), and both may contribute to HPA axis regulation (Holmes et al. 1986; Antoni et al. 1990). As well, CRH neurons increase in the human PVN with age (Raadsheer et al. 1994), there is an age-dependent colocalization of CRH and AVP in the human PVN (Raadsheer et al. 1993), and larger AVP neurons have been found in the PVN of elderly men compared with those in elderly women (Ishunina and Swaab 1999). These findings suggest that AVP may play a more important role in the regulation of the HPA axis in elderly versus young subjects and in elderly men versus elderly women, consistent with the magnitude of the AVP:ACTH correlations in our elderly and young men.
There are other sexually dimorphic areas of the brain in humans, the most prominent being in the medial preoptic area of the hypothalamus (Swaab 1995; Swaab et al. 1995), which also has been implicated in HPA axis regulation (Viau and Meaney 1996; Herman et al. 1996). Because these systems receive direct or indirect cholinergic input, they also might mediate the effects of PHYSO on the HPA axis differently in young and elderly females and males.

This study contributes to a small but growing number of neuroendocrine studies in which age $\times$ sex interactions have been reported, young adult men responding to a greater degree than young adult women, and elderly women either not differing from, or responding to a greater degree than, elderly men. For example, Gelfin et al. (1995) indicated that ACTH and cortisol responses to stimulation with the serotonin-1A receptor agonist, ipsapirone, were greater in young versus elderly men and, conversely, greater in elderly versus young women. Similarly, Seeman et al. (2001) reported that salivary cortisol responses to a standardized cognitive challenge were greater in young men compared with young women and, conversely, were greater in elderly women compared with elderly men. Other patterns of response differences, however, also have been noted; for example, Heuser et al. (1994) indicated that both young and elderly women secreted significantly more cortisol in response to dexamethasone suppression followed by CRH stimulation than did their male counterparts.

In these studies, however, it has not always been made clear how many of the elderly women were receiving estrogen replacement therapy, and sex steroid levels have not been reported. It therefore would be of interest to study elderly women with the same pharmacological or psychological challenge both prior to and following estrogen replacement therapy, to determine the effect of hormone replacement on their HPA axis responses. Hypothetically, estrogen therapy would reduce the hormone responses of postmenopausal women to those of their premenopausal counterparts. The effect of androgen replacement therapy in elderly men found to have reduced circulating androgens also would be important to consider.

In conclusion, the present study suggests that central cholinergic systems can influence HPA axis hormone secretion differently in elderly versus young adult women and men. Either central cholinergic systems themselves might be sexually dimorphic/diergic, or central cholinergic stimulation might affect other, sexually dimorphic/diergic systems that influence hormone release. The available evidence, although scanty, points toward the latter. Subsequent studies will address specific muscarinic and nicotinic components of this system in both young and elderly subjects, based on our findings with cholinergic receptor antagonist pretreatment followed by PHYSO stimulation, as well as stimu- 
lation by nicotine itself, in female and male laboratory rats (Rhodes et al. 2001a, 2001b).

\section{ACKNOWLEDGMENTS}

This study was supported by National Institute of Mental Health research grant $\mathrm{MH} 28380$.

\section{REFERENCES}

Anonymous (1992): Proposal of standard methods for the determination of enzyme catalytic concentrations in serum and plasma at 37 degrees C. II. Cholinesterase (acylcholine acylhydrolase, EC 3.1.1.8). Working Group of Enzymes, German Society for Clinical Chemistry. Eur J Clin Chem Clin Biochem 30:163-170

Antoni FA (1993): Vasopressinergic control of pituitary adrenocorticotropin secretion comes of age. Front Neuroendocrinol 14:76-122

Antoni FA, Fink G, Sheward WJ (1990): Corticotrophinreleasing peptides in rat hypophysial portal blood after paraventricular lesions: a marked reduction in the concentration of corticotrophin-releasing factor- 41 , but no change in vasopressin. J Endocrinol 125:175-183

Asplund R, Åberg H (1991): Diurnal variation in the levels of antidiuretic hormone in the elderly. J Int Med 229:131-134

Assenmacher I, Szafarcyzk A, Alonso G, Ixart G, Barbanel G (1987): Physiology of neural pathways affecting CRH secretion. Ann NY Acad Sci 512:149-161

Boschetti N, Brodbeck U, Jensen SP, Koch C, Norgaard-Pedersen B (1996): Monoclonal antibodies against a C-terminal peptide of human brain acetylcholinesterase distinguish between erythrocyte and brain acetylcholinesterases. Clin Chem 42:19-23

Calogero AE (1995): Neurotransmitter regulation of the hypothalamic corticotropin-releasing hormone neuron. Ann NY Acad Sci 771:31-40

Coiro V, Volpi R, Capretti L, Colla R, Caffarri G, Vescovi PP, Chiodera P (1995): Dopaminergic and cholinergic control of arginine-vasopressin secretion in type I diabetic men. Eur J Clin Invest 25:412-417

Ehrlich G, Viegas-Pequignot E, Ginzberg D, Sindel L, Soreq $\mathrm{H}$, Zakut H (1992): Mapping the human acetylcholinesterase gene to chromosome $7 \mathrm{q} 22$ by fluorescent in situ hybridization coupled with selective PCR amplification from a somatic hybrid cell panel and chromosomesorted DNA libraries. Genomics 13:1192-1197

Ellman GL, Courtney KD, Andres V Jr, Featherstone RM (1961): A new and rapid colorimetric determination of acetylcholinesterase activity. Biochem Pharmacol 7:88-95

Ferrari E, Cravello L, Muzzoni B, Casarotti D, Paltro M, Solerte SB, Fioravanti M, Cuzzoni G, Pontiggia B, Magri F (2001): Age-related changes of the hypothalamic-pituitary-adrenal axis: pathophysiological correlates. Eur J Endocrinol 144:319-329

Ferrini M, Piroli G, Frontera M, Falbo A, Lima A, De Nicola AF (1999): Estrogens normalize the hypothalamic-pituitary-adrenal axis response to stress and increase gluco- corticoid receptor immuno-reactivity in hippocampus of aging male rats. Neuroendocrinology 69:129-137

First MB, Spitzer RL, Gibbon M, Williams JBW (1996): Structured clinical interview for DSM-IV axis I disorders non-patient edition (SCID-I/NP, version 2.0). New York, Biometrics Research Department, NY State Psychiatric Institute

Fisher DA, Nelson JC (2001): Endocrine testing. In DeGroot LJ, Jameson JL (eds), Endocrinology, Fourth Edition. Philadelphia, W.B. Saunders, pp 2574-2600.

Gelfin Y, Lerer B, Lesch K-P, Gorfine M, Allolio B (1995): Complex effects of age and gender on hypothermic, adrenocorticotrophic hormone and cortisol responses to ipsapirone challenge in normal subjects. Psychopharmacology 120:356-364

Genç S, Gürdöl F, Güvenç S, Karg1 Y (1997): Variations in serum cholinesterase activity in different age and sex groups. Eur J Clin Chem Clin Biochem 35:239-240

Gregg CM (1985): The compartmentalized hypothalamoneurohypophysial system: evidence for a neurohypophysial action of acetylcholine on vasopressin release. Neuroendocrinology 40:423-429

Hamilton M (1967): Development of a rating scale for primary depressive illness. Br J Soc Clin Psychol 6:278-296

Herman JP, Prewitt CM, Cullinan WE (1996): Neuronal circuit regulation of the hypothalamo-pituitary-adrenocortical stress axis. Crit Rev Neurobiol 10:371-394

Heuser IJ, Gotthardt U, Schweiger U, Schmider J, Lammers CH, Dettling M, Holsboer F (1994): Age-associated changes of pituitary-adrenocortical hormone regulation in humans: importance of gender. Neurobiol Aging 15:227-231

Hibberd C, Yau JLW, Seckl JR (2000): Glucocorticoids and the ageing hippocampus. J Anat 197:553-562

Hofman MA (1997): Lifespan changes in the human hypothalamus. Exp Gerontol 32:559-575

Holmes MC, Antoni FA, Aguilera G, Catt KJ (1986): Magnocellular axons in passage through the median eminence release vasopressin. Nature 319:326-329

Ishunina TA, Swaab DF (1999): Vasopressin and oxytocin neurons of the human supraoptic and paraventricular nucleus; size changes in relation to age and sex. J Clin Endocrinol Metab 84:4637-4644

Janowsky DS, Overstreet DH (1995): The role of acetylcholine mechanisms in mood disorders. In Bloom FE, Kupfer DJ (eds), Psychopharmacology: The Fourth Generation of Progress. New York, Raven Press, pp 945-956.

Lewis DA, Sherman BM, Kathol RG (1984): Analysis of the specificity of physostigmine stimulation of adrenocorticotropin in man. J Clin Endocrinol Metab 58:570-573

Lupien SJ, Nair NP, Briere S, Maheu F, Tu MT, Lemay M, McEwen BS, Meaney MJ (1999): Increased cortisol levels and impaired cognition in human aging: implication for depression and dementia in later life. Rev Neurosci 10:117-139

McEwen BS (1999): Stress and the aging hippocampus. Front Neuroendocrinol 20:49-70

McWilliam C, Wood N, Copeland JRM, Taylor WH (1990): Erythrocyte acetyl cholinesterase in elderly patients with dementia and depression compared with normal controls. Age Ageing 19:104-106 
Michels KM, Meeker RB, Hayward JN (1991): Muscarinic cholinergic control of vasopressin secretion from the acute hypothalamoneurohypophysial explant. Neuroendocrinology 54:219-226

Ohmori N, Itoi K, Tozawa F, Sakai Y, Sakai K, Horiba N, Demura H, Suda T (1995): Effect of acetylcholine on corticotropin-releasing factor gene expression in the hypothalamic paraventricular nucleus of conscious rats. Endocrinology 136:4858-4863

Okuda H, Shioda S, Nakai Y, Nakayama H, Okamoto M, Nakashima T (1993): The presence of corticotropinreleasing factor-like immunoreactive synaptic vesicles in axon terminals with nicotinic acetylcholine receptorlike immunoreactivity in the median eminence of the rat. Neurosci Lett 161:183-186

Pascualy M, Peskind ER, Wingerson D, van Belle G, Veith RC, Dorsa DM, Raskind MA (1995): Lack of cholinergic regulation of vasopressin and norepinephrine responses to hypertonic saline in humans. Psychoneuroendocrinology 20:679-691.

Peskind ER, Raskind MA, Wingerson D, Pascualy M, Thal LJ, Dobie DJ, Veith RC, Dorsa DM, Murray S, Sikkema C, Galt SA, Wilkinson CW (1995): Enhanced hypothalamic-pituitary-adrenocortical axis responses to physostigmine in normal aging. J Gerontol 50A:M114-M120

Peskind ER, Raskind MA, Wingerson D, Pascualy M, Thal LJ, Dobie DJ, Wilkinson CW (1996): Hypothalamic-pituitary-adrenocortical axis responses to physostigmine: effects of Alzheimer's disease and gender. Biol Psychiatry 40:61-68

Raadsheer FC, Sluiter AA, Ravid R, Tilders FJH, Swaab DF (1993): Localization of corticotropin-releasing hormone (CRH) neurons in the paraventricular nucleus of the human hypothalamus; age-dependent colocalization with vasopressin. Brain Res 615:50-62

Raadsheer FC, Oorschot DE, Verwer RWH, Tilders FJH, Swaab DF (1994): Age-related increase in the total number of corticotropin-releasing hormone neurons in the human paraventricular nucleus in controls and Alzheimer's disease: comparison of the disector with an unfolding method. J Comp Neurol 339:447-457

Raskind MA, Peskind ER, Veith RC, Wilkinson CW, Federighi D, Dorsa DM (1990): Differential effects of aging on neuroendocrine responses to physostigmine in normal men. J Clin Endocrinol Metab 70:1420-1425

Raskind MA, Wilkinson CW, Peskind ER (2001): Aging and Alzheimer's disease. In Pfaff D, Arnold AP, Etgen AM, Fahrbach SE, Moss RL, Rubin RT (eds), Hormones, Brain and Behavior. New York, Academic Press (in press)

Rhodes ME, Rubin RT (1999): Functional sex differences ("sexual diergism") of CNS cholinergic systems, vasopressin, and hypothalamic-pituitary-adrenal axis activity in mammals: a selective review. Brain Res Rev 30: 135-152

Rhodes ME, O'Toole SM, Wright SL, Czambel RK, Rubin RT (2001a): Sexual diergism in rat hypothalamic-pituitaryadrenal axis responses to cholinergic stimulation and antagonism. Brain Res Bull 54:101-113

Rhodes MR, O'Toole SM, Czambel KR, Rubin RT (2001b):
Male-female differences in rat hypothalamic-pituitaryadrenal axis responses to nicotine stimulation. Brain Res Bull 54:681-688

Rivier C, Smith M, Vale W (1990): Regulation of adrenocorticotropic hormone $(\mathrm{ACTH})$ secretion by corticotropin releasing factor (CRF). In De Souza EB, Nemeroff CB (eds), Corticotropin Releasing Factor: Basic and Clinical Studies of a Neuropeptide. Boca Raton, CRC Press, pp 175-203.

Rubin RT, Poland RE, Lesser IM, Winston RA, Blodgett ALN (1987): Neuroendocrine aspects of primary endogenous depression I. Cortisol secretory dynamics in patients and matched control subjects. Arch Gen Psychiatry 44:329-336

Rubin RT, Phillips JJ, Sadow TF, McCracken JT (1995): Adrenal gland volume in major depression. Increase during the depressive episode and decrease with successful treatment. Arch Gen Psychiatry 52:213-218

Rubin RT, Phillips JJ, McCracken JT, Sadow TF (1996): Adrenal gland volume in major depression: relationship to basal and stimulated pituitary-adrenal cortical axis function. Biol Psychiatry 40:89-97

Rubin RT, Sekula LK, O'Toole S, Rhodes ME, Czambel RK (1999a): Pituitary-adrenal cortical responses to low-dose physostigmine and arginine vasopressin administration in normal women and men. Neuropsychopharmacology 20:434-446

Rubin RT, O'Toole SM, Rhodes ME, Sekula LK, Czambel RK (1999b): Hypothalamo-pituitary-adrenal cortical responses to low-dose physostigmine and arginine vasopressin administration: sex differences between major depressives and matched control subjects. Psychiatry Res 89:1-20

Seeman TE, Robbins RJ (1994): Aging and hypothalamicpituitary-adrenal response to challenge in humans. Endocr Rev 15:233-260

Seeman TE, Singer B, Wilkinson CW, McEwen B (2001): Gender differences in age-related changes in HPA axis activity. Psychoneuroendocrinology 26:225-240

Shapira M, Tur-Kaspa I, Bosgraaf L, Livni N, Grant AD, Grisaru D, Korner M, Ebstein RP, Soreq H (2000): A transcription-activating polymorphism in the ACHE promoter associated with acute sensitivity to anti-acetylcholinesterases. Hum Mol Genet 9:1273-1281

Swaab DF (1995): Development of the human hypothalamus. Neurochem Res 20:509-519

Swaab DF, Gooren LJ, Hofman MA (1995): Brain research, gender and sexual orientation. J Homosexuality 28:283-301

Tsagarakis S, Grossman A (1990): Central neuroregulation of hypothalamic corticotropin-releasing hormone (CRH41) secretion. J Endocrinol Invest 13:765-775

Tuomisto J, Männistö P (1985): Neurotransmitter regulation of anterior pituitary hormones. Pharmacol Rev 37:249-332

Viau V, Meaney MJ (1996): The inhibitory effect of testosterone on hypothalamic-pituitary-adrenal responses to stress is mediated by the medial preoptic area. J Neurosci 16:1866-1876

Whitnall MH (1993): Regulation of the hypothalamic corticotropin-releasing hormone neurosecretory system. Progr Neurobiol 40:573-629 